\title{
A European Physics Education Network
}

\author{
Hendrik Ferdinande from the University of Ghent, who chaired the conference \\ Physics Studies for Tomorrow's Europe (Ghent, 7-8 April 1995) and its Scientific \\ Committee, summarises the meeting's conclusions and recommendations, \\ many of which will be taken up by a proposed SOCRATES Academic Develop- \\ ment Programme for physics called the European Physics Education Network.
}

Physics being universal does not of itself have a European dimension. Yet the European dimension in physics teaching is vital if we are to build upon the diversity of approaches to physics. The conference Physics Studies for Tomorrow's Europe was perhaps the first occasion on which authorities on physics teaching could take a detailed look at how the European dimension in physics studies and training can be enhanced. Discussions were based on National Reports [1] prepared by National Experts (members of the conference's Scientific Committee). They include a considerable amount of invaluable data describing the present status of the teaching of physics in 24 European countries, as well as discussions of future needs and the implementation of special measures.

The meeting, which went under the title of a European Evaluation Conference, was sponsored by the European Commission's (EC) new Directorate-General for Education, Training and Youth (DG-XXII). Some 20 of these thematic conferences in various academic disciplines are being held in order to provide the basis for creating SOCRATES Academic Cooperation Projects (see below), where the level of funding will be decided once proposals have been evaluated. The conference also aimed to prepare for other aspects of the SOCRATES programme so support was provided by the current TEMPUS and ERASMUS programmes. These are now largely absorbed in SOCRATES which aims to develop a European dimension at all levels of education.

Science in general and physics in particular through their search for understanding are by their very natures cultural activities. In their application they are also vital for our modern high-technology society since they promote technological progress and economic growth. The conference concluded that physics teaching provides scientific literacy in the sense that it shapes the analytical thinking of society, which is important for solving complicated social problems. This perspective also implies that the popularization of science must be encouraged and that good practice in physics teaching is essential at the secondary school and university levels for both non-physicists and for physicists. For this one needs well-qualified teachers who can teach physics in an attractive, up-to-date way.

The National Reports which were summarised by P.J. Brussaard from Utrecht ("Present Day Trends") and by R.A. Ricci from Legnaro ("Suggestions for Future Directions") clearly demonstrated that studies at universities and equivalent institutions

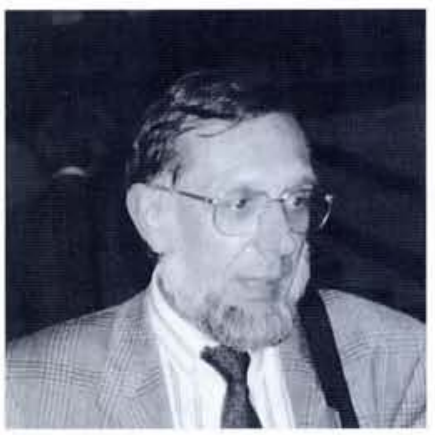

for a degree or diploma in physics train young "physicists" for work in a variety of environments, notably research, industry and teaching. In addition, physics graduates will increasingly occupy positions outside physics in the strict sense of the term, where flexibility, creativity, intuition, problem-solving, communication skills, and teamwork are crucial. Basic and intermediate training in physics should be oriented towards all of these four career opportunities, so courses must be sufficiently general in scope. They should include interdisciplinary material and have connections to the social and behavioural sciences as well as to economic and management studies. On the other hand, advanced (and, in particular, doctoral) studies in physics should allow students to acquire a profound knowledge in specialized fields and to obtain high-quality research training. To achieve these latter aims, institutions must undertake research in at least some of the active fields of present-day physics.

Since physics as a scientific discipline does not possess a European dimension in itself, the presentations by European Commission officials, notably I.V. Mitchell who is responsible in DG-XXII for the higher education aspects of SOCRATES (see insert), stressed that a European dimension in the teaching of physics must be achieved with the help of information networks and supple-

Hendrik Ferdinande is a member of the Mobility Committee that manages the European Mobility Scheme for Physics Students (EMSPS). He is seen here in front of the EMSPS stand at the last EPS General Conference.
Published by EPS to inform members. Editor: P.G. Boswell, EPS, BP 69, CH-1213 Petit-Lancy 2. E-mail: peter.boswell@cern.ch Fel: $+41-22-7931130$ - Fax: +41-22-79313 17

\section{MAY - JUNE 1995}

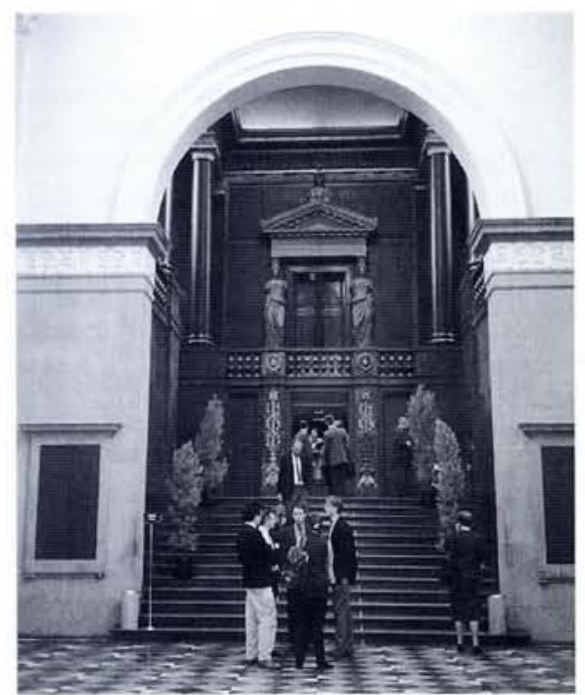

Some 170 participants from 25 countries attended the conference Physics Studies for Tomorrow's Europe which was held in the Aula complex of the University of Ghent. It was organized by the University of Ghent, chaired by Hendrik Ferdinande, and sponsored by the EPS student mobility scheme and the EPS Interdivisional Group on Physics Education. The meeting was supported by various European Union programmes and by the EC's DG-XXII as a thematic evaluation conference to prepare initiatives to be proposed to the recently launched SOCRATES programme.

mentary measures such as student and teaching staff mobility, attendance at international schools and language training. The ERASMUS part of SOCRATES will primarily use a new institution-based approach to channel funds to universities while essentially keeping the ERASMUS Interuniversity Cooperation Programmes that provide networks between academic coordinators.

\section{Problems Identified}

Research and teaching in physics in Europe have good reputations: being highly diversified they constitute a richness which must be preserved. Despite this high-quality, P.J. Brussaard described a number of problems. Some of them are general, such as the decreasing respect for, and status of, teachers. Others, such as excessively long physics courses, concern particular regions or countries. The specific problems related to the topics that were singled out by the conference as being in need of special attention, possibly via an EC-supported European Physics Education Network (EUPEN - see insert), are described below together with the proposed recommendations.

Others specific problems include: 
- A decreasing interest in physics by secondary school students and a decreasing number of university-level physics students in some countries.

- Physics is considered difficult and unattractive by secondary school students and by non-physics students at the university level. - Physics teaching in secondary schools in some countries seems to lag well behind modern developments in physics.

- A low proportion of women among physics students and teaching/research staff (pronounced in northern Europe).

- The effective duration of physics studies is often (much) longer than the official one, even given the fact that in some cases the official duration of first-degree studies is already relatively long, and sometimes much too long.

- The drop-out rate in some countries is high (although it should, of course, not be decreased by sacrificing quality); little systematic information is available about the reasons why students abandon the study of physics.

- Physics teaching is isolated from industry and research laboratories.

- The pronounced diversity in the structure of the physics curricula in Europe may create problems connected with mobility and recognition (e.g., the mathematical approach in continental Europe as compared with a more experimental approach in the UK and Ireland).

- Open and distance learning is little used in physics education.

There are some problems that are common to all scientific disciplines and can be addressed by national and/or institutional bodies. These include:

- Academic calendars (subdivision of the academic year; beginning and end of course and examination periods) are very different from country to country. This impedes student and teacher mobility.

- In some countries, pre-university foreignlanguage training is inadequate and does not allow students to make efficient use of mobility schemes.

\section{Four Themes}

The Physics Studies for Tomorrow's Europe conference identified four themes that could be addressed by a SOCRATES network as an Academic Development Programme. They are:

- Curriculum development.

- Intensive programmes, notably for secondary school teachers, one of several possible new initiatives.

- Mobility of students and teachers which effectively represents the application of new methodologies to physics teaching.

- Educational resources and the quality of teaching.

\section{a) Curriculum development}

There is little exchange of information and little common effort on curriculum development, and on research on physics education, in some countries and within particular institutions. The great diversity of physics curricula thus leads to difficulties in academic recognition for study periods and in the recognition of diplomas, and more generally in comparing curricula. Proposed solutions to these problems seek:

- Widely available information on university physics courses (structure of studies; degrees awarded; content of studies; summary of the content of each course; ECTS credits attributed to each course; assessment and grading scale used with respect to the ECTS grading scale). The generation of information and its availability on the WorldWide Web (WWW) need to be encouraged. Conferences on the content of physics programmes and on new ways to teach physics should be organized regularly; comparability studies are required.

- Curriculum development projects need to be promoted and they should publish intermediate and final results in an easily accessible way via WWW, electronic bulletin boards, specialized journals, etc.

- Short-duration programmes awarding lower degrees (e.g., B.Sc.) which emphasize physics are of interest to east and central Europe (E\&CE). Dissemination of the experience gathered by west European universities should be encouraged.

\section{b) Intensive programmes}

There are many advanced research schools and workshops, but usually attendance is not formally recognized with a view to obtaining an advanced degree. Moreover,

\section{Physics Studies for Tomorrow's Europe \\ NATIONAL REPORTS}

\section{L'enseignement de la physique pour l'Europe de demain} RAPPORTS NATIONAUX

Prepared for a European Evaluation Conference, University of Ghent, 7-8 April 1995. Published by EPS \& the University of Ghent, 1995 (220 pages)

\section{Available in English or in French}

Orders: H. Ferdinande, Universiteit Gent, Proeftuinstraat 86 , B-9000 Gent (fax: +32-926466 99; e-mail: hendrik.ferdinande @ rug. ac.be) with BEF 200-- mailing charge/copy transferred to Postal Cheque Account No.: 000-1667186-47 (specify language version).

information on schools is not readily available to all students and many schools are not synchronized. There are also few programmes for in-service training and few refresher courses for secondary school teachers, especially at a European or international level. There is also little contact between teachers and university staff teaching introductory physics and thus little effort to smooth the transition from secondary school to university. Recommendations include:

\section{SOCRATES at a Glance}

\section{The European Community Action Programme} in the Field of Education (1995-99; 850 MECU)

Approved by the European Union Council of Ministers and by Parliament in March 1995 to develop quality education by encouraging cooperation and by supporting complementary measures while respecting each Member State's responsibility for the content and organization of teaching. Aims to develop the European dimension at all levels of learning via mobility, academic recognition, cooperation, information exchange, and distance education. SOCRATES is open to east and central European countries (E\&CE) but it is unclear how they will be able to participate in 1995. Guidelines and information package to be issued in June 1995. Managed by the European Commission's Directorate-General for Education, Training and Youth (DG-XXII), formerly the Task Force on Human Resources. Overview available on WWW at http://europa.cec.lu/

Higher Education: expansion of the former ERASMUS programme; $>55 \%$ of budget. Initiatives for E\&CE will focus initially on generating information describing courses so that course credits can be transferred during mobility stays (some $70 \%$ of ERASMUS mobility stays now involve at least partial recognition).

Activities within Institutional Contracts: Postponed for one year to give universities time to prepare the internal consultative procedures needed for the new Institutional Contracts involving financing through universities based on coordinated work plans submitted by the universities by mid-1996. Hence ERASMUS Interuniversity Cooperation Projects will continue for an extra year (i.e., for the 1996/7 academic year). Activities:

- organization of student \& teaching staff exchanges

- implementation of the European Credit Transfer Scheme (ECTS)

- joint curriculum development $\quad$-intensive programmes

- preparatory visits/study visits - development of integrated language courses

Activities outside Institutional Contracts: 1995 announcements for 1996 implementation.

- Academic Development Projects to develop a European dimension within various disciplines through university cooperation.

- stimulation measures (open \& distance learning; analyses/surveys; association activity).

\section{Student Mobility Grants organized through national agencies.}

School Education: COMENIUS to bring the European concept to schools; $>10 \%$ of budget; new action calls for proposals starting in 1995 and some activities planned for 1995. Activities: school partnerships; in-service training for teachers.

Horizontal Measures ( $>25 \%$ of budget)

- Promotion of language skills: expansion of the original LINGUA which terminated in 1994; some activities planned for 1995.

- Open and distance learning: new activity; pilot projects in 1995.

- Exchange of information and experience: EURYDICE (information network/statistics: statutory activity so no calls); ARION (visits scheme for decision makers; calls in 1995); NARIC (academic recognition information centres; statutory activity).

- Complementary measures: association support; awareness generation. 
Towards EUPEN Most of the specific recommendations stemming from the Physics Studies for Tomorrow's Europe conference need further study before they can be transformed into actions. They also cannot be implemented at the same time so priorities must be set. Moreover, once launched, actions should be monitored and improvements proposed and carried out. The conference therefore proposed as a main conclusion the creation of a permanent forum, tentatively called the European Physics Education Network (EUPEN), which would be responsible for various promotional, advisory and operational tasks.

The idea is that EUPEN would apply for support from the European Commission under the SOCRATES heading to organize a thematic Academic Development Programme (ADP) for physics within the so-called "SOCRATES space" (essentially the European Union and the six east and central European countries that participate in the SOCRATES programme). It may also be possible to seek funding from other sources.

EUPEN would operate in close connection with EPS, and more specifically with the EPS Interdivisional Group on Physics Education, consisting of the Forum on Education, the University Teaching Section and the European Mobility Scheme for Physics Students (EMSPS). It would also co-operate with similar bodies acting in other parts of the world (e.g., Asian Physics Education Network, Arab Physics Education Network, Council of InterAmerican Physics Education Conferences) or on the global scale (e.g., International Commission of Physics Education).

The network would be open to all the European universities (and equivalent institutions) that award degrees in physics, to national and European societies for physicists, for physics teachers, and for physics students (e.g., the International Association of Physics Students), and to industry and international and national research laboratories.

The conference endorsed the proposal that the Scientific Committee acts as a working party for setting up the EUPEN network by formulating terms of reference and by filing an application for an ADP to SOCRATES. Moreover, institutions in eastern and central Europe (E\&CE) participate successfully with universities from western Europe in exchange programmes such as the EU's TEMPUS programme and the EPS European Mobility Scheme for Physics Students which received grant support from the The Soros Foundations. Physics can set a promising example by continuing and intensifying this collaboration in education and training across all of Europe. So integrating institutions from E\&CE in the proposed EUPEN network is vital, and SOCRATES envisages this.

- Adaptation of the ECTS credit system represents one way to promote research schools and other intensive programmes as part of standard physics curricula (at the advanced, mainly doctoral, level and maybe at the undergraduate level).

- Advanced schools and other types of intensive courses for secondary school teachers must be organized in order to update teachers on developments in physics and on teaching methods applied to physics. Information about advanced schools must widely disseminated and the schools should be synchronized.

- School teachers and university staff, especially those responsible for introductory courses, should establish contacts and coordinate their programmes.

\section{c) Mobility}

In the case of students, mobility at both the undergraduate and doctoral levels seems to be lower than for other disciplines, and there are large imbalances between in- and out-flows in some countries. The potential for a student to spend time in industry and in research centres is not adequately exploited. The quality and impact of mobility stays and exchange visits (course recognition; amount of study time lost; improvement of foreign language skills; job prospects) remain largely unknown.

Student mobility can be promoted by:

- Including all institutions in exchange schemes so that all students may profit from mobility if they wish to do so. This may take some time to achieve so special measures are needed for countries with particularly low in- and out-flows.

- Widely available information on possible exchanges distributed using modern com- munication means (e.g., the ECTS information package and the EMSPS database) and by generalizing the ECTS and EMSPS student application forms. These measures will facilitate the establishment of study programmes and recognition by enabling credit transfer.

- Students/potential employer contacts, especially if "external" expertise can be exploited by extending student mobility to project work for a diploma or M.Sc. thesis performed in industry or in research centres (France's CIFRE initiative [2] provides a good example).

Student mobility during advanced (mainly doctoral) studies is promoted by:

- Recognized research schools.

- doctor europeus or some other (European) qualification that is attached to the degree awarded by the home institution (conditions: stay of at least three months in one or more foreign universities/research laboratories; international thesis panel; paper corresponding to thesis published in a refereed scientific journal; part of the thesis defence in a foreign language). France operates a scheme [3] of this type.

In the case of teachers, while the mobility of physics research staff is well developed this is not so for teachers. Moreover, universities seldom call on physicists working in industry to give lectures. One solution is:

- A much higher priority and funding level for the mobility of teaching staff between institutions and between industry and universities. Mobility of the former type is not only beneficial for the staff members themselves and their institutions, but also allows students who do not move to acquire some of the benefits otherwise obtained through student mobility. d) Educational resources

It is clearly necessary to continuously monitor quantitatively and qualitatively all aspects of the teaching of physics and to propose measures for improvements. It will thus be useful to:

- Evaluate educational resources and teaching quality on a regular basis at the European level.

An assessment meeting for representatives who took part in the various thematic conferences is planned for July 1995 to coordinate approaches to the European Commission. It will effectively constitute the first step on the road to forming a much-needed European forum for physics education.

[1] Physics Studies for Tomorrow's Europe: National Reports (220 pages); Post-Deadline National Reports (30 pages). Prepared for a European Evaluation Conference, University of Ghent, 7-8 April 1995 (EPS; University of Ghent; 1995).

[2] Convention Industrielle de la Formation par la Recherche; see [1], p.64.

[3] Doctorat Européen programme introduced by some French universities; see [1], p.67.

\section{Executive Committee Decisions}

The EPS Executive Committee meeting in Geneva on 16-17 June decided as follows:

Secretariat: To propose to Council to consolidate the Geneva and Budapest Secretariats on a science park in Mulhouse within about 12 months. Five sites had been put forward. Budget: To accept the Auditors Report for 1994 which sees an accumulated deficit of $62 \mathrm{kSFR}$. To provide with the normal annual budget a breakdown according to activities. Europhysics News: To accept, subject to final negotiations, a 3-year agreement with Springer-Verlag whereby Springer is responsible for production and commercial aspects. To enlarge the Editorial Board to 17 to provide wider representation. It will meet 1-2 times p.a. to decide policy and long-term planning.

Internet: To form an Internet Coordination Group reporting to the Executive Committee. EMSPS: To accept 5 new participating institutions in the European Mobility Scheme for Physics Students (EMSPS), bringing the total number to 169. To approve the proposal that EPS sends representatives to the European Union's European Assessment Conference which will coordinate the outcome of a series of thematic conferences on education needs. Collaborating Society: To recommend to Council that the European Optical Society be accepted as a Collaborating Society.

Honorary Members: To appoint a working group to select Honorary Members that would be proposed to the General Meeting of members during the EPS-10 General Conference (Sevilla, 9-13 September 1996).

Quantum Electronics and Optics Division: To accept a proposal to establish a biannual Quantum Electronics Prize of EPS.

Physics and Society Action Committee: To provide financial support to help prepare a meeting with science writers at EPS-10 and to carry out a survey of employment.

International Association of Physics Students (IAPS): To support the IAPS in preparing an IAPS/EPS information leaflet.

Council Meeting: To change the dates of the 1996 Council Meeting (Lisbon) to 22-23 March. 